\title{
Incidental Thyroid Carcinoma in Benign Thyroid Disease: A Cohort Study
}

\author{
${ }^{1}$ Diluka Pinto, ${ }^{1}$ Nalinda Munasinghe, ${ }^{1}$ Pramod C Chandrasinghe, ${ }^{2}$ Ranil Fernando
}

\section{ABSTRACT}

Aim: An incidental thyroid carcinoma (ITC) is a thyroid malignancy that is not clinically or cytologically detected preoperatively. The incidence of ITC is between $10 \%$ to $20 \%$ in the literature. A study was undertaken to assess the incidence of ITC in patients undergoing total thyroidectomy for benign disease of the thyroid to University Surgical Unit, North Colombo Teaching Hospital (NCTH), Sri Lanka.

Materials and methods: Prospective cohort study was undertaken from November, 2002 to October, 2015. Patients with palpable thyroid nodules were assessed with fine needle aspiration cytology (FNAC) and ultrasound scan (USS) to ascertain benign thyroid disease (BTD). Hormone assays were conducted to detect thyroid status. All patients with BTD who underwent total thyroidectomy were included in the study. Histopathological assessments were made by a panel of pathologists. Patients with autoimmune thyroiditis (AIT) were excluded due to the known association with malignancy of the thyroid. Post-thyroidectomy histopathological diagnoses were collected prospectively and patients with ITC were identified. Statistical analysis was done using statistical package for the social sciences (SPSS) software, version 20.

Results: Hundred and sixty seven patients $(n=167)$ who fulfilled the inclusion criteria were analysed (Male-20, female-147, median age $=40.25$ year, range 28 year-62 year). ITC was found in 19 patients with an incidence of $11.38 \%$. No significant association was noted with morphology, biochemical status of the thyroid or gender.

Conclusion: Incidence of ITC is $11.38 \%$ in this cohort. Incidence of ITC being approximately 1:10 emphasizes the need to consider total thyroidectomy in the management of BTD.

Keywords: Goiter, Thyroid cancer, Thyroid carcinoma, Thyroid surgery, Thyroidectomy.

How to cite this article: Pinto D, Munasinghe N, Chandrasinghe PC, Fernando R. Incidental Thyroid Carcinoma in Benign Thyroid Disease: A Cohort Study. World J Endoc Surg 2018;10(3):154-156.

Source of support: Nil

Conflict of interest: None

\footnotetext{
${ }^{1}$ Lecturer, ${ }^{2}$ Professor

${ }^{1}$ Department of Surgery, Faculty of Medicine, University of Kelaniya, Ragama, Western, Sri Lanka

${ }^{2}$ Department of Surgery, Faculty of Medicine, University of Kelaniya, Colombo, Western Sri Lanka

Corresponding Author: Diluka Pinto, Lecturer, Department of Surgery, Faculty of Medicine, University of Kelaniya, Ragama, Western Sri Lanka, e-mail: d.pinto@kln.ac.lk
}

\section{INTRODUCTION}

Incidental thyroid carcinoma (ITC) or occult carcinoma of the thyroid is a thyroid cancer which is not diagnosed preoperatively. The term 'occult thyroid carcinoma' has come into surgical use since the mid-20th century. ${ }^{1}$ Routine clinical, radiological, biochemical or cytological assessments fail to detect the presence of a carcinoma. The postoperative histopathological analysis reveals the presence of ITC.

Majority of benign disease of the thyroid is managed non-operatively: ${ }^{2}$ Current literature reports an incidence of ITC varying between 10 to $20 \% .^{3,4}$ The prevalence of goiter in Sri Lanka is about $6.8 \% .^{5}$

A previous study at the same unit which included patients with AIT had shown an incidence of ITC as $8.8 \% .{ }^{5}$ Hence, the current study was undertaken with the exclusion of patients with AIT which is a well-known risk factor for the development of carcinoma of the thyroid.

Presence of ITC in approximately $1 / 10$ patients with benign disease warrants re-evaluation of options in the management of BTD.

\section{MATERIALS AND METHODS}

This prospective cohort study was conducted from November 2002 to October 2015. All consenting patients who underwent total thyroidectomy for BTD at the professorial surgical unit, NCTH were included in the study.

Clinical, biochemical, radiological (USS) and cytological (FNAC) assessment was done pre-operatively in all patients.

Clinical and radiological features of the goiter were used to categorize participants as having a multinodular goiter (MNG), solitary thyroid nodule (STN) or diffuse goiter. Biochemical assessment of the thyroid status grouped them to be hyperthyroid $(<0.4 \mathrm{mU} / \mathrm{L})$, euthyroid (0.4-4.0 mU/L) and hypothyroid ( $>4.0 \mathrm{mU} / \mathrm{L})$. All patients were made euthyroid before surgery.

Preoperative cytological findings of Thy 2 was taken as the inclusion criterion. Other cytological types, including carcinoma of the thyroid and the presence of autoimmune thyroiditis, were taken as exclusion criteria. ${ }^{6}$

All surgeries were performed by a single surgeon at a professorial surgical unit of NCTH. Total thyroidectomies were performed through a standard collar incision 
with capsular dissection. Nerve encountering (Recurrent laryngeal nerve/ external branch of superior laryngeal nerve) and parathyroid preservation, auto-transplantation techniques were adhered to routinely. Completion thyroidectomies were done for solitary thyroid nodules.

Analysis of the pre and post-operative cytological and histopathological assessments was performed by the Department of Pathology, University of Kelaniya, Sri Lanka.

Characteristics of preoperatively the two goiters which showed malignancy in post-operative histology ( $\mathrm{n}=19$ ); were compared using Fisher's exact test using SPSS software, version 20.

Ethical approval was granted by the Ethics Review Committee of Faculty of Medicine, University of Kelaniya, Sri Lanka.

\section{RESULTS}

A total of 167 patients were included in the study. ITC was noted in 19 patients (Table 1). The median age was 41.21 years in females and 37.4 years in males with a range of 28 to 62 years. The incidence of ITC was $11.38 \%$.

Clinical features of the 19 ITC patients showed 14 MNGs (73.68\%), 4 STNs (21.05\%) and one diffuse goiter $(5.26 \%)$. None of the lesions were detected clinically. Morphology and ITC did not show any significant association $(\mathrm{MNG} \mathrm{p}=0.139, \mathrm{STN} \mathrm{p}=0.089)$

Biochemical assessment of the ITC population revealed 14 patients were euthyroid $(73.68 \%)$ and five were hyperthyroid $(26.31 \%)$. None were hypothyroid. Preoperative thyroid status did not show any significant association to the occurrence of ITC (Euthyroid $p=0.545$, Hyperthyroid $\mathrm{p}=0.331$ )

Postoperative histopathological findings showed 12 papillary carcinomas (63.15\%) and seven follicular carcinomas (36.85\%). Medullary carcinoma was not detected. All histologically detected lesions were less than $2 \mathrm{~cm}$.

\section{DISCUSSION}

The worldwide prevalence of ITC is about 10 to $20 \%$ according to the literature. ${ }^{3,4}$ Issues and concerns regarding ITC has not been adequately addressed in the literature. Neighbouring India had recorded a prevalence of $20.3 \%{ }^{4}$ The prevalence is likely to be higher as some individuals with goiter may not present to a medical facility. $^{7}$ The incidence of ITC in this cohort is $11.38 \%$. This

Table 1: Gender distribution of the cohort

\begin{tabular}{llll}
\hline & BTD & ITC & Total \\
\hline Male & $15(8.98 \%)$ & $5(2.99 \%)$ & $20(11.98 \%)$ \\
Female & $133(79.64 \%)$ & $14(8.38 \%)$ & $147(88.02 \%)$ \\
Total & $148(88.62 \%)$ & $19(11.37 \%)$ & 167 \\
\hline
\end{tabular}

incidence is higher than previously recorded $(8.8 \%) .^{5} \mathrm{It}$ is worthwhile noting that the prevalence of goiter in Sri Lanka is $6.8 \% .^{8}$

On analysis, MNG or STN had no significant association with ITC in this study. Current literature is in line with these findings. ${ }^{9}$ Biochemical status of the thyroid did not yield any significant association with the occurrence of ITC. Most were euthyroid. Other studies including a meta-analysis by Negro et al. in 2013 showed no significant relationship between low TSH (hyperthyroid) and incidental carcinoma of the thyroid. ${ }^{10}$

Post-operative histopathological diagnoses showed the dominant histological type of ITC as papillary carcinoma. This is in accordance with the current literature. ${ }^{11}$ Follicular carcinomas were found in $36.85 \%$ in this study. ITC with follicular histology was noted in a range of 16 to $42 \%$ by several authors. ${ }^{4,12}$

Most patients with BTD do not undergo surgery in the current setting. ${ }^{2}$ Total thyroidectomy for BTD has gained popularity over the years. ${ }^{13}$ The complications associated with total thyroidectomy are minimal in experienced hands. ${ }^{14-16}$ Friguglietti et al. noted that the common complications of transitory/permanent hypoparathyroidism, hematoma requiring surgical intervention or transitory/ permanent RLN damage are not significantly higher in total thyroidectomy than in a sub-total procedure. ${ }^{14}$ Consideration of total thyroidectomy for BTD should be re-evaluated, especially in long-standing MNG where there is a risk of malignancy. ${ }^{17,18} \mathrm{An}$ incidence of $11.38 \%$ in ITC and the difficulties in reoperation favors the use of total thyroidectomy in BTD. ${ }^{16}$

\section{CONCLUSION}

The incidence of ITC is $11.38 \%$ in this cohort. The incidence of ITC being approximately 1:10 emphasizes the need to consider total thyroidectomy in the management of BTD.

\section{ACKNOWLEDGMENTS}

Authors would like to thank all the patients who volunteered for this research project.

\section{REFERENCES}

1. Klinck GH, Winship T. Occult sclerosing carcinoma of the thyroid. Cancer. 1955;8(4):701-706.

2. Fernando P, Ratnatunga C, Fernando R, Lowe D, Udugama C, Wattegama S. Management of Goitre [Internet]. 1st ed. Sri lanka: College of Surgeons Sri Lanka; 2007 [cited 3 July 2017]. Available from: http://http://www.slcog.lk/img/ guidelines/Other\%20national\%20Gidelines/Surgeons/ Book\%201/Management\%20of\%20Goitre.pdf

3. Koutelidakis I, Laskou S, Kapoulas S, Kalaitzis S, Papadakis $\mathrm{G}$, Evangelatos $\mathrm{P}$, et al. Incidental thyroid cancer in patients 
undergoing total thyroidectomy for benign disease. Hellenic Journal of Surgery. 2015 Jul 1;87(4):307-8.

4. Nanjappa N, Kumar A, Swain SK, Aroul TT, Smile SR, Kotasthane D. Incidental thyroid carcinoma. Indian Journal of Otolaryngology and Head \& Neck Surgery. 2013 Jan 1;65(1):37-39.

5. Fernando R, Mettananda DS, Kariyakarawana L. Incidental occult carcinomas in total thyroidectomy for benign diseases of the thyroid. Ceylon Medical Journal. 2009 Apr 21;54(1): 4-6.

6. Azizi G, Keller JM, Lewis M, Piper K, Puett D, Rivenbark KM, et al. Association of Hashimoto's thyroiditis with thyroid cancer. Endocrine-related cancer. 2014 Dec 1;21(6):845-852.

7. Russell S. Treatment-seeking behaviour in urban Sri Lanka: trusting the state, trusting private providers. Social science \& medicine. 2005 Oct 31;61(7):1396-1407.

8. Fernando R, Pathmeswaran A, Pinto MD. Epidemiology of goitre in Sri Lanka in the post-iodization era. Ceylon Medical Journal. 2015;60(2):41-44.

9. Miccoli P, Minuto MN, Galleri D, D'Agostino J, Basolo F, Antonangeli $\mathrm{L}$, et al. Incidental thyroid carcinoma in a large series of consecutive patients operated on for benign thyroid disease. ANZ journal of surgery. 2006 Mar 1;76(3):123126.

10. Negro R, Valcavi R, Toulis K. Incidental thyroid cancer in toxic and nontoxic goiter: is TSH associated with malignany rate? Results of a meta-analysis. Endocrine Practice. 2012 Nov 27;19(2):212-218.
11. Boucek J, Kastner J, Skrivan J, Grosso E, Gibelli B, Giugliano $\mathrm{G}$, et al. Occult thyroid carcinoma. ActaOtorhinolaryngologicaltalica. 2009 Dec;29(6):296.

12. Jabbar MQ, CABMS MD, Mutlak NS, Hussein WA, Sulaiman TI, CABMS FF. Incidental thyroid carcinoma.

13. Reeve TS, Delbridge L, Cohen A, Crummer P. Total thyroidectomy. The preferred option for multinodular goiter. Annals of surgery. 1987 Dec;206(6):782.

14. Friguglietti CU, Lin CS, Kulcsar MA. Total thyroidectomy for benign thyroid disease. The Laryngoscope. 2003 Oct 1;113(10):1820-1826.

15. Colak T, Akca T, Kanik A, Yapici D, Aydin S. Total versus subtotal thyroidectomy for the management of benign multinodular goiter in an endemic region. ANZ journal of surgery. 2004 Nov 1;74(11):974-978.

16. Barakate MS, Agarwal G, Reeve TS, Barraclough B, Robinson $\mathrm{B}$, Delbridge LW. Total thyroidectomy is now the preferred option for the surgical management of Graves' disease. ANZ journal of surgery. 2002 May 1;72(5):321-324.

17. Zuberi LM, Yawar A, Islam N, Jabbar A. Clinical presentation of thyroid cancer patients in Pakistan-AKUH experience. Journal-Pakistan Medical Association. 2004 Oct;54(10):526527.

18. Mathai V, Idikula J, Fenn AS, Nair A. Do Long Standing Nodular Goitres Result in Malignancies?. ANZ Journal of Surgery. 1994 Mar 1;64(3):180-182. 